appreciation of the relevant geological conditions. In the new era opening out, the unified coal industry, with all its potentialities and its capacity to quicken or retard the tempo of our whole national life, must receive all the assistance that geology can provide in planning ahead, in suggestions for economic working, in interpreting structures, in reading doubtful sequences, etc.

The task of the geologist in the coalfields is to correlate and assess all the information already available, to advise as to future developments, and to follow these up much more closely than it has been possible to do in the past. This cannot be achieved by periodic efforts or by a discontinuous service. Research in the coalfields is not a series of separate ad hoc pieces of investigation but a continuous service which requires a full-time staff. It is only in this way that geology can be enabled to take its proper place in the economic life of the country. It is only in this way, too, that the gaps in our knowledge of many aspects of Carboniferous geology can be filled, and a more and more broadly based synthesis built up. The coal-mining industry has now become a national trust, and it is as such that it must be regarded by all; the issues are clear-cut and indeed vital, and it is for geologists to see that geology plays its part in the difficult times ahead.

\section{ZOOLOGISTS IN WAR AND PEACE}

$\mathrm{D}^{\mathrm{r}}$ R. EDWARD HINDLE, in the opening remarks of his presidential address to Section D (Zoology), mentioned that in view of the exceptional conditions under which they met, he proposed to devote his address to an account of some of the work in which zoologists had been engaged during the past few years. He first referred to war-time activities and gave a brief account of the application of the principles of animal coloration, known as camouflage, and also of some work on anti-fouling. Special attention was devoted to the contributions of zoologists to the maintenance of our food supplies, without which it is very doubtful whether the country could have been adequately fed. An important section of this work was the protection of our food stocks against animal pests, and mention was made of the work of the Bureau of Animal Population at Oxford on rodent control and the development of the Infestation Division of the Ministry of Food. The activities of the latter were dealt with at some length, since it developed as a direct result of war conditions and was staffed mainly by graduates in zoology.

Various attempts were made during the War to increase food supplies. These included extending the use of unmarketable fish which, in the English Channel alone, resulted in the production of about $1 \frac{1}{2}$ tons a week of excellent fish-paste from fish that was formerly wasted. The experiments at Loch Sween (Argyll) on the possibility of raising the fertility of a given area of the sea by the addition of nitrates and phosphates were also considered.

Zoologists took a prominent part in some branches of operational research. In particular, they were closely involved in the practical development of radar in connexion with gun-laying devices for antiaircraft guns, and the development of ' $\mathrm{H}_{2} \mathrm{~S}$ ', an apparatus used for the localization of targets. Eventually this was fitted in various aircraft, and its use resulted in enemy submarines being brought under control during the first half of 1943. Moreover, they did not become a serious menace again until the invention of the 'Schnorkel' in. 1945.

Zoologists were found to be particularly well-fitted to cope with the early difficulties of radar, since by their training they become accustomed to handling large numbers of uncontrollable variables.

Some of the peace-time activities of zoologists were then referred to, with special emphasis on the work of entomologists in checking the serious losses in our agricultural products, stored products, and in the prevention of disease. To take only one item, the loss of grain in India, due to rodents, insects and moulds, has been estimated to amount to $12-15$ per cent, and a saving of 10 per cent would be sufficient to prevent a famine. In Africa the Colonial Development Scheme, involving the expenditure of some $£ 24,000,000$ in the production of ground-nuts, would mean the use of mechanized agriculture on an unprecedented scale in that continent, and would create conditions favourable to the spread of animal pests and disease. Dr. Hindle expressed the hope that the number of professional biologists employed in this project would be commensurate with this expenditure.

The subject of taxonomy was then discussed, and the increasing difficulty of getting accurate identifications of species. An Empire Biological Service, somewhat analogous to the Fish and Wild Life Service in the United States, was suggested, as this might offer the possibility of establishing a pool of taxonomic specialists who could be attached not only to national and provincial museums in Britain, but also to corresponding institutions in the British Empire. Ultimately, this might be extended on an international basis. Finally, Dr. Hindle stressed the educational value of an academic training in zoology, which was out of all proportion to its economic possibilities; and appealed for a return to a less mechanistic training of the younger generation.

\section{GEOGRAPHY IN WAR AND PEACE}

$\mathrm{N}$ her presidential address to Section E (Geography), Irof.E. G. R. Taylor points out that, while everyone admits that 'circumstances of place', that is, geography, are relevant to human history and human affairs, it remains true that geographical circumstances are normally regarded as 'accidents'; and as being, moreover, of so obvious a character that it needs no trained geographer to point them out, much less being such as to deserve analysis in detail. This over-simplified idea of geography, which can be exemplified in the writings of historians, economists, military commentators and others, is responsible for the fact that the subject receives no mention in the schemes for revised university curricula aimed at the provision of a more balanced general education embracing both science and the humanities. Nor is it included in plans for the advancement and endowment of the social sciences. The pure scientist, too, rejects geography since (except in certain limited aspects) it is not susceptible of study by the method of controlled experiment. Yet departments of geography are over-full, and chairs in geography multiply faster than they can be effectively filled. Ordinary people are recognizing that the regional differentiation of the world's surface (although they would not thus define it) lies behind some of our most crucial problems, and is at the root 